\title{
Rapid diagnostic tests to detect asymptomatic malaria in primary health care facilities in hypoendemic areas
}

\author{
LAMBOK SIAHAAN1, A-G, HARUN ALRASYID², A, C, D, RATNA AKBARI'3, A, c, D, PUTRI EYANOER 4, A, c, D, \\ MERINA PANGGABEAN ${ }^{1}, \mathbf{A}, \mathbf{B}, \mathbf{F}, \mathbf{G}$, YOAN PANGGABEAN ${ }^{1,} \mathbf{A}, \mathbf{B}, \mathbf{F}, \mathbf{G}$
}

${ }^{1}$ Parasitology Department, Medical Faculty, University of Sumatera Utara, Medan, Indonesia
${ }^{2}$ Nutrition Department, Medical Faculty, University of Sumatera Utara, Medan, Indonesia
${ }^{3}$ Clinical Pathology Department, Medical Faculty, University of Sumatera Utara, Medan, Indonesia
${ }^{4}$ Community Medicine Department, Medical Faculty, University of Sumatera Utara, Medan, Indonesia

A - Study Design, B - Data Collection, C - Statistical Analysis, D - Data Interpretation, E - Manuscript Preparation, F - Literature Search, G - Funds Collection

Summary Background. Early detection and appropriate treatment of malaria, as well as elimination of vectors, will prevent the transmission of the disease. Nowadays, malaria treatment is only administered after the illness has been laboratory confirmed using, e.g., rapid diagnostic tests (RDTs), when microscopy is not available. RDTs are commonly used in patients reporting to primary health care (PHC) providers with a fever. If left untreated, asymptomatic malaria could be a source of disease transmission and may potentially lead to an outbreak. Yet, the detection of asymptomatic malaria is difficult, as parasitological tests are only performed in symptomatic patients, i.e. those presenting with a fever.

Objectives. The aim of the study was to assess the rates of asymptomatic malaria cases in hypoendemic areas. Malaria was detected through RDTs that were performed at PHC facilities in the Batubara District in the North Sumatera Province in Indonesia. Material and methods. Data was collected from two PHC providers and four villages with the highest rate of malaria cases. Malaria was diagnosed based on RDTs and then confirmed by microscopic examination, which remains the gold standard. Results. The study group included 504 patients. The overall sensitivity, specificity, positive predictive value (PPV) and negative predictive value (NPV) of the RDTs for the diagnosis of any malarial species were $77.9 \%, 41.9 \%, 59.4 \%$ and $63.5 \%$, respectively. The proportion of asymptomatic malaria was $22.1 \%$. Asymptomatic malaria cases were mainly due to Plasmodium vivax. Conclusions. Periodic mass blood surveys are necessary to identify asymptomatic malaria cases in hypoendemic areas. Key words: fever, RDTs, asymptomatic malaria, PHC.

Siahaan L, Alrasyid H, Akbari R, Eyanoer P, Panggabean M, Panggabean Y. Rapid Diagnostic Tests to Detect Asymptomatic Malaria in Primary Health Care Facilities in Hypoendemic Areas. Fam Med Prim Care Rev 2016; 18(4): 470-472, doi: 10.5114/ fmpcr.2016.63703.

\section{Background}

Even today, malaria is still the most common mosquito-borne disease in the Batubara District in the North Sumatera Province in Indonesia. Fluctuations of the prevalence of malaria occur frequently in many places in Indonesia [1]. The cause of fluctuations in the case of malaria is failed detection of asymptomatic malaria. Patients of asymptomatic malaria generally do not come to health care facilities. These individuals can be a source of new transmission in subsequent malaria infection and form a reservoir of parasites in vector [2]. The transmission will form the reservoir in a vector, especially in hypoendemis malaria, and could potentially be the cause of an increase in cases of malaria [3].

There have been continuous efforts to eliminate malaria in the region, yet, because cases of asymptomatic malaria are not usually treated, these efforts have failed. Asymptomatic carriage of malaria pathogens may facilitate the transmission of the disease and potentially be the cause of an outbreak and, as a consequence, a rise in the prevalence of malaria. Microscopy continues to be the 'gold standard' for malaria diagnosis; unfortunately, it is not always available at primary health care $(\mathrm{PHC})$ facilities in resource-limited settings, due to its high cost, lack of skilled manpower, ac- cessories and the reagents required [4]. Meanwhile, rapid diagnostic tests (RDTs) are being used as a diagnostic tool for malaria as a substitute for microscopic examination $[5,6]$.

The efficacy of RDTs is considered similar to microscopic examination in hyperendemic areas according to some experts. In addition, RDTs have been shown to be cost effective and less time consuming in the management of malaria [4]. Detection of asymptomatic malaria is an important task which is mainly carried out in PHC facilities and is the key element of the malaria elimination program.

\section{Objectives}

The aim of this study was to assess the rates of asymptomatic malaria cases in hypoendemic areas. Malaria was detected through RDTs that were performed at PHC facilities in the Batubara District in the North Sumatera Province in Indonesia.

\section{Material and methods}

The study was carried out to detect asymptomatic infections of malaria using RDTs. The data was collected from two 
PHC facilities and four villages from November to December 2015. This study involved 504 patients (49.8\% females and $50.2 \%$ males), from 1 to 70 years of age, living in the Batubara District. All randomly selected participants were screened using active case detection (ACD) and passive case detection (PCD). Axillary temperature was measured in all patients upon recruitment. Fever was defined as an axillary temperature $\geq 37.5^{\circ} \mathrm{C}$. Every patient willing to participate in this study was examined using RDTs. Malaria diagnosis was confirmed by microscopic examination, which continues to be the gold standard for the detection of malaria. The RDTs used in this study included: Monotes Test Device, Malaria $\mathrm{Pf} / \mathrm{Pv}$ Ag Rapid Test (whole blood), with relative sensitivity of $100 \%$, relative specificity of $98.7 \%$ and an overall agreement of $98.9 \%$. The sensitivity, specificity, positive predictive value (PPV) and negative predictive value (NPV) of the RDTs were assessed for malaria detection.

Ethics approval and authorization were obtained from the ethical committee of the Medical Faculty of the University of Sumatera Utara. Before collecting the data, each participant was clearly informed about the objective of the study, and verbal permission from the head of each household was obtained.

\section{Results}

A total of 504 patients were examined throughout the study period. There were 345 patients with fever and 159 patients without fever. The RDTs that were performed on 159 patients without fever demonstrated that 58 patients $(36.5 \%)$ had asymptomatic malaria (Table 1$)$. In the group of patients without fever, the majority was asymptomatic or presented with weakness (Table 2). Almost all cases of asymptomatic malaria were due to Plasmodium vivax.

\begin{tabular}{|l|l|l|l|l|l|l|}
\hline \multicolumn{7}{|l|}{ Table 1. Classification of malaria } \\
\hline $\begin{array}{l}\text { Age } \\
\text { (years) }\end{array}$ & \multicolumn{2}{|l|}{ Sex } & \multicolumn{2}{l|}{ Fever (+) } & \multicolumn{2}{l|}{ Fever (-) } \\
\cline { 2 - 7 } & M & F & $\begin{array}{l}\text { llinical } \\
\text { malaria }\end{array}$ & $\begin{array}{l}\text { non } \\
\text { malaria }\end{array}$ & $\begin{array}{l}\text { asymp- } \\
\text { tomatic } \\
\text { malaria }\end{array}$ & $\begin{array}{l}\text { non } \\
\text { malaria }\end{array}$ \\
\hline$\leq 5$ & 21 & 35 & 18 & 20 & 4 & 14 \\
$6-12$ & 63 & 56 & 51 & 40 & 12 & 19 \\
$13-19$ & 57 & 76 & 52 & 42 & 25 & 15 \\
$20-50$ & 98 & 76 & 77 & 35 & 14 & 42 \\
$>50$ & 14 & 8 & 7 & 3 & 3 & 11 \\
\hline
\end{tabular}

\begin{tabular}{|l|l|l|l|}
\hline \multicolumn{4}{|c|}{ Table 2. Classification of asymptomatic malaria } \\
\hline Symptoms & $\begin{array}{l}\text { P. falciparum } \\
(\%)\end{array}$ & P. vivax (\%) & $\begin{array}{l}\text { P. falciparum } \\
\text { + P. vivax (\%) }\end{array}$ \\
\hline Cough & 0 & 1.7 & 5.2 \\
Weakness & 0 & 22.4 & 12.1 \\
Diarrhea & 0 & 5.2 & 0 \\
Vomiting & 0 & 8.6 & 0 \\
Headache & 1.7 & 3.4 & 1.7 \\
Myalgia & 0 & 1.7 & 1.7 \\
Symptomless & 1.7 & 22.4 & 10.3 \\
\hline
\end{tabular}

The prevalence of asymptomatic malaria, based on the results of RDTs, was $22.1 \%$. The RDTs were positive in $205 / 263$ (77.9\%; sensitivity) cases of fever and negative in 101/241 (41.9\%; specificity) patients without fever. The PPV for malaria infection in patients with fever was 205/345 $(59.4 \%)$, and NPV was 101/159 (63.5\%). The sensitivity, specificity, PPV and NPV results of RDTs for the detection of malaria infection are presented according to age groups (Table 3).

\begin{tabular}{|l|l|l|l|l|l|}
\hline \multicolumn{6}{|l|}{ Table 3. Accuracy of Rapid Diagnostic Test } \\
\hline $\begin{array}{l}\text { Age } \\
\text { (years) }\end{array}$ & $\begin{array}{l}\text { Asymp- } \\
\text { tomatic } \\
\text { malaria } \\
(\%)\end{array}$ & $\begin{array}{l}\text { Sensitivity } \\
(\%)\end{array}$ & $\begin{array}{l}\text { Specificity } \\
(\%)\end{array}$ & $\begin{array}{l}\text { PPV } \\
(\%)\end{array}$ & $\begin{array}{l}\text { NPV } \\
(\%)\end{array}$ \\
\hline$\leq 5$ & 1.5 & 81.8 & 41.2 & 47.4 & 77.8 \\
$6-12$ & 4.6 & 81 & 32.2 & 56 & 61.3 \\
$13-19$ & 9.5 & 67.5 & 26.3 & 55.3 & 37.5 \\
$20-50$ & 5.3 & 84.6 & 54.5 & 68.8 & 75 \\
$>50$ & 1.1 & 70 & 78.6 & 70 & 78.6 \\
\hline
\end{tabular}

\section{Discussion}

Many countries have increased efforts to control malaria by introducing elimination programs. These efforts include changes in malaria diagnosis, i.e. not only diagnosing patients with clinical symptoms of the disease, but also those at risk of malaria $[7,8]$.

Asymptomatic malaria was found in malaria patients who presented no clinical symptoms of fever during initial inspection but showed the presence of Plasmodium sp. on microscopic examination. The persistence of gametocytes in the blood of patients can be a source of new transmission in subsequent malaria infection (gametocyte carrier). Late treatment of asymptomatic malaria detected in patients will increase the chances of transmission of malaria infection and hinder the achievement of malaria elimination [2].

In the early course of the disease, asymptomatic malaria does not present any clinical symptoms, but when antiparasite immunity failed to suppress parasite density, clinical symptoms will appear later [2]. Clinical symptoms are expected to appear two to four weeks later [9, 10]. Dysregulation of the immune system causes asymptomatic malaria, and this will turn into symptomatic malaria and will not be detectable by microscopic (submicroscopic malaria) [11, 12].

The epidemiology of asymptomatic malaria is different in each region and depends on the endemicity. The prevalence of asymptomatic malaria is influenced by many factors, such as age, the density of parasites and insect bites [13]. Asymtomatic malaria may also occur in patients with chronic malaria infection [14]. The biggest challenge today is the accuracy of a diagnostic tool for detecting asymptomatic malaria [2], especially in primary health care.

RDTs, which use the principle of immunochromatography to detect antigens, have been increasingly used as a substitute for microscopic methods, as these are not always readily available in PHC facilities. The efficacy of RDTs, however, may be affected by the target antigen, the number of malaria cases, the density of parasites and the prevalence of parasite species in each region [15]. In rural areas, RDTs are only being used for patients reporting with fever, which is primarily due to certain logistical constraints. This research has shown that $32 \%$ of malaria cases were diagnosed in asymptomatic patients, leading to the conclusion that they would not have been detected if the RDTs had only been performed on patients with fever. It can be concluded that the malaria elimination program can only be successful when asymptomatic malaria has been eradicated [16]

\section{Conclusions}

Asymptomatic malaria could be detected when RDTs were performed in all inhabitants, not only used in symptomatic patients. Periodic mass blood surveys are necessary to identify asymptomatic malaria cases in hypoendemic areas. 
Acknowledgments. We thank the health workers of the health care services in the Batubara District, as well as the holders of the malaria program in the Batubara District, North Sumatera. We also thank all the participants in this study.

Source of funding: This work was funded by the authors' resources.

Conflict of interest: The authors declare no conflict of interests.

\section{References}

1. Indonesian Health Ministry. Malaria Epidemiology in Indonesia. In: Buletin Jendela Data dan Informasi Kesehatan. 2011 (annual report, unpublished).

2. Lindblade KA, Steinhardt L, Samuels A, et al. The silent threat: asymptomatic parasitemia and malaria transmission. Expert Rev Anti Infect Ther 2013; 11(6): 623-639.

3. Ahmed S, Galagan S, Scobie H, et al. Malaria hotspots drive Hypoendemic Transmission in Chittagong Hill Districts of Bangladesh. PLoS ONE 2013; 8(8): e69713, doi: 10.1371/journal.pone.0069713.

4. Kyabayinze DJ, Asiimwe C, Nakanjako D, et al. Use of RDTs to improve malaria diagnosis and fever case management at primary health care facilities in Uganda. Malar J 2010; 9(200), doi: 10.1186/1475-2875-9-200.

5. Noedl H, Yingyuen K, Laoboonchai A, et al. Sensitivity and specificity of an antigen detection ELISA fir malaria diagnosis. Am J Trop Med Hyg 2009; 75(6): 1205-1208.

6. Bisoffi Z, Gobbi F, Angheben A, et al. The role of rapid diagnostic tests in managing malaria. PLoS Med 2009; 6(4): e1000063, doi: 10.1371/journal.pmed.1000063.

7. Mohanna MA, Ghouth AS, Raja'a YA. Malaria signs and infection rate among asymptomatic schoolchildren in Hajr valley, Yemen. East Mediterr Health J 2007; 13(1): 35-40.

8. Suárez MMC, Cuervo P, Leoratti FM, et al. Cross sectional study reveals a high percentage of asymptomatic Plasmodium vivax infection in the Amazon Rio Negro area, Brazil. Rev Inst Med Trop Sao Paulo 2007; 49(3): 159-164.

9. Bereczky S, Montgomery SM, Troye-Blomberg M, et al. Elevated anti-malarial IgE in asymptomatic individuals is associated with reduced risk for subsequent clinical malaria. Int J Parasitol 2004; 34(8): 935-942.

10. Magesa SM, Mdira KY, Babiker HA. Diversity of Plasmodium falciparum clones infecting children living in a holoendemic area in north-eastern Tanzania. Acta Trop 2002; 84(2): 83-92.

11. Barbosa S, Gozze AB, Lima NF, et al. Epidemiology of disappearing Plasmodium vivax malaria: a case study in rural Amazonia. PLoS Negl Trop Dis 2014; 8: e3109, doi: 10.1371/journal.pntd.0003109.

12. Okell LC, Bousema T, Griffin JT, et al. Factors determining the occurrence of submicroscopic malaria infections and their relevance for control. Nat Commun 2012; 3(1237), doi: 10.1038/ncomms2241.

13. Geiger C, Agustar HK, Compaoré G, et al. Declining malaria parasite prevalence and trends of asymptomatic parasitaemia in a seasonal transmission setting in north-western Burkina Faso between 2000 and 2009-2012. Malar J 2013; 12(27), doi: 10.1186/1475-2875-12-27.

14. Cheng Q, Cunningham J, Gatton ML. Systematic review of sub-microscopic $P$. vivax infections: prevalence and determining factors. PLoS Negl Trop Dis 2015; 9(1): e3413, doi: 10.1371/journal.pntd.0003413.

15. Bisoffi Z, Sirima SB, Menten J, et al. Accuracy of a rapid diagnostic test on the diagnosis of malaria infection and of malaria - attributable fever during low and high transmission season in Burkina Faso. Malar J 2010; 9(192): 1-14, doi: 10.1186/14752875-9-192.

16. Vinetz JM and Gilman RH. Asymptomatic Plasmodium parasitemia and the ecology of malaria transmission. Am J Trop Med Hyg 2002; 66(6): 639-640.

Tables: 3

Figures: 0

References: 16

Received: 05.10.2016

Revised: 28.10.2016

Accepted: 04.11.2016

Address for correspondence:

Lambok Siahaan, MD, PhD

Jl dr Mansyur 5

Medan 20131

Indonesia

Tel.: +628126561772

E-mail: lamboksiahaan_fkusu@yahoo.com 